\title{
Foxl2 gene and the development of the ovary: a story about goat, mouse, fish and woman**
}

\author{
Daniel BARON $^{\mathrm{a}}$, Frank BATISTA ${ }^{\mathrm{b}}$, Stéphane CHAFFAUX ${ }^{\mathrm{c}}$,

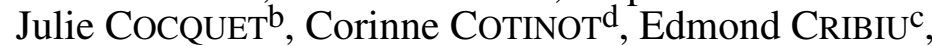 \\ Elfride DE BAEREE ${ }^{\mathrm{e}}$, Yann GUIGUEN ${ }^{\mathrm{a}}$, Francis JAUBERT ${ }^{\mathrm{b}}$, \\ Eric PAILHOUX ${ }^{\mathrm{d}}$, Maëlle PANNETIER ${ }^{\mathrm{d}}$, Daniel VAIMAN ${ }^{\mathrm{b}}$, \\ Bernard VIGIER $^{\mathrm{d}}$, Reiner VEITIA ${ }^{\mathrm{b}}$, Marc FELLOUS ${ }^{\mathrm{b} *}$ \\ a Équipe Sexualité et Reproduction, INRA-SCRIBE, Département PHASE, Campus de Beaulieu, \\ 35042 Rennes Cedex, France \\ b INSERM U709, Pavillon Baudelocque, 123, Boulevard de Port Royal, 75014 Paris, France \\ c Laboratoire de Génétique Biochimique et Cytogénétique, Domaine du Vilvert Centre INRA, \\ 78350 Jouy-en-Josas, France \\ d UMR Biologie du Développement et Reproduction, Domaine du Vilvert Centre INRA, \\ 78350 Jouy-en-Josas, France \\ e University of Gand, Belgium
}

\begin{abstract}
In this review, we describe recent results concerning the genetics of sex determination in mammals. Particularly, we developed the study of the FOXL2 gene and its implication in genetic anomalies in goats (PIS mutation) and humans (BPES). We present the expression of FOXL2 in the ovaries of different species.
\end{abstract}

ovary / comparative genomics / FOXL2 / PIS / BPES

\section{SEX DETERMINATION IN MAMMALS}

The $\mathrm{Y}$ chromosome was first revealed in 1959 in human male (46 XY) and not in female (46XX) caryotypes. Since then, it seems clear that the testis determining gene(s) is located on this $\mathrm{Y}$ chromosome (see review in [1]). Then, it took thirty years to identify this gene by studying sex-reversed
$46 \mathrm{XX}$ males or $46 \mathrm{XY}$ women. In fact several of these sex-reversed females carry a deletion of the shorter arm of the Y chromosome, a region that is present in sexreversed $46 \mathrm{XX}$ males. The SRY gene (Sexdetermining Region of the Y chromosome) was isolated in this region. After the discovery of $S R Y$ in 1990 [2], some other genes involved in testis differentiation have been isolated through the observation of clinical

\footnotetext{
* Corresponding author: fellous@ cochin.inserm.fr

** This presentation reviews a research project carried out for over ten years, starting in 1992, financed by INRA and INSERM, and encouraged by Professor Charles Thibault.
} 
cases presenting sex-reversal (discordance between the cytogenetic and gonadal sex). Nevertheless, up to date many genes remain to be discovered, as well as the molecular mechanisms and gene interactions involved in the differentiation cascade of the gonad. This is even more relevant for the ovary differentiation pathway.

\section{SRY}

This single-exon gene is specifically expressed in male gonads. It encodes a 204 amino acid protein comprising three regions, one of which is the DNA binding domain named "HMG Box" (for High Mobility Group). Sequence homology studies have shown that the HMG Box is the only region of SRY conserved among mammal species. Different observations have confirmed that $S R Y$ is the testis determining factor: (i) the presence of point mutations in this gene in 46, XY women with gonadal dysgenesis, (ii) the additive transgenesis of Sry in XX mice which induces a female-to-male sexreversal [3].

Since its discovery, it has been shown that $S R Y$ induces cell proliferation leading to the following: (i) a size increase of the $\mathrm{XY}$ gonads, (ii) differentiation of Sertoli cells and their organization in seminiferous cords, (iii) differentiation of a testis-specific vasculature. However, for the moment, the molecular target(s) of SRY remain unknown.

Furthermore, mutations of this gene are involved in only $20 \%$ of $46, \mathrm{XY}$ sex-reversed cases and $80 \%$ of $46, \mathrm{XX}$ sex-reversed males. Thus, there must be other genes involved in the testis differentiation cascade. By positional cloning, some of them have been isolated in 46, XY females with gonadal dysgenesis (WT1, SOX9, DAX1, etc.). On the contrary, no gene responsible for XX male sex-reversal has been identified, but we propose a model in order to explain the development of an XX male phenotype in the absence of $S R Y$ (Fig. 1, Z model). An animal model, fitting with the characteristics of this theoretical model has been recently studied in mutated goats.

\section{PIS MUTATION IN GOATS}

The PIS syndrome (Polled Intersex Syndrome) was first observed in the early 20th century. It associates the absence of horns (dominant) to sex-reversal in XX animals (recessive). When heterozygous hornless goats are crossed among them, a Mendelian segregation for the hornless phenotype is observed. On the contrary, XX animals (homozygous for the hornless mutation) have a male sex-reversal phenotype similar to $46, \mathrm{XX} S R Y$-negative masculin phenotype in men. The histology and immunohistochemistry of the gonads of these animals have confirmed the presence of seminiferous cords and the expression of $\mathrm{AMH}$ (Anti-Müllerian Hormone) produced by Sertoli cells; however, no germ cells are found at puberty [4].

After several years of goat genome cartography and genetic linkage analysis, the PIS locus has been mapped on the caprine chromosome 1. In humans, the Blepharophimosis Ptosis Epicantus inversus Syndrome (BPES) has been mapped on the chromosome 3 equivalent region. This syndrome associates eyelid malformations to ovarian dysgenesis in $46, \mathrm{XX}$ patients. It has been shown that loss-of-function mutations of FOXL2 are responsible for this syndrome [5].

After a long work of positional cloning, the PIS mutation has been characterized as a deletion of a $12 \mathrm{~kb}$ region responsible for the cis-regulation of at least three genes: FOXL2, PISRT1 and PFOXic. This corresponds to a metagenomic complex: the PIS region acts as a regulatory element controlling the transcriptional expression of several genes [6]. The abnormal expression of these three genes is in accordance with the mode of inheritance observed for the different phenotypes: dominant by a gain-offunction through over expression of these 
A - Normal XY male (SRY-positive)

$\mathbf{Z}$

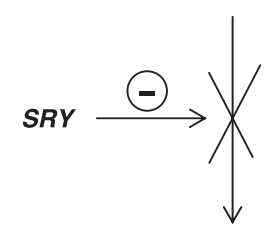

Male-specific
genes Activation

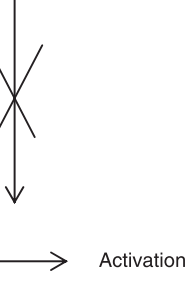

Z-

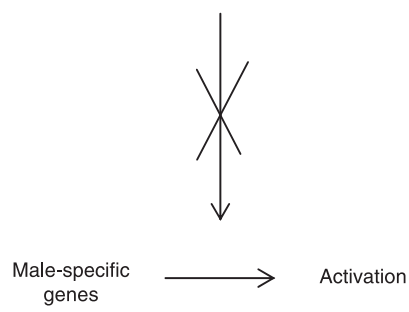

B - Normal XX female (SRY-negative)

$\mathbf{Z}$

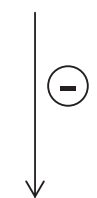

Male-specific

genes

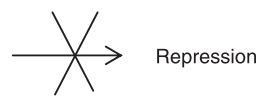

Figure 1. Regulatory cascade hypothesis for mammalian sex determination and an explanation for sex reversal in XX male $S R Y^{-}$and XY SRY+ individuals. (A) In wild-type males, the SRY protein is present and inhibits $\mathrm{Z}$ by acting as a repressor of $\mathrm{Z}$ synthesis (as drawn) or by inhibiting the activity of $Z$ (not drawn). Male sex determination is therefore uninhibited by $Z$ and can proceed. (B) In wild-type femalas, the SRY protein is lacking. Therefore, the $\mathrm{Z}$ protein is able to inhibit male sex determination, and female sex determination occurs. (C) XX individuals lacking SRY who exhibit male phenotypes (male with sexual ambiguities or true hermaphroditism) are proposed to be defective in the $Z$ gene since they are homozygous for a $Z^{-}$mutation (indicated by - ). These individuals are therefore able to express male sex determination. (D) XY individuals who carry an intact $S R Y$ gene can exhibit female phenotypes if they carry a mutation at the $Z$ locus $\left(Z^{\mathrm{i}}\right)$ that renders $Z$ insensitive to repression by the SRY protein. The $Z$ protein is therefore produced and can inhibit male sex determination, allowing female sex determination to occur.

three genes in horns, since the heterozygous state; recessive for the sex-reversal phenotype due to an absence of expression of these three genes in the developing ovary leading to testis differentiation.

In wild-type animals, the regulatory element PIS inhibits the expression of these three genes in horns (Fig. 2). By contrast, the PIS region is necessary for their expression in the ovaries beginning with the first stages of their differentiation. In XY males, $S R Y$ would block the regulatory element PIS and then prevent the gonad expression of these three genes. The deletion of this 


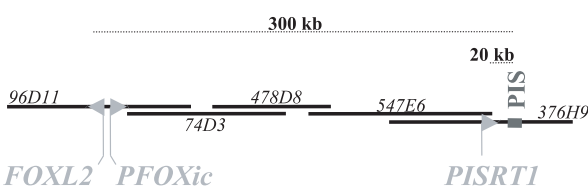

Figure 2. Schematic representation of the PIS region. The PIS mutation is represented on the right. It contains transcriptional regulatory elements of three genes (arrowheads), PISRT1, PFOXic and FOXL2, located respectively at 20 and $300 \mathrm{~kb}$ from PIS. The lines represent the different BACs encompassing the region. BACs' addresses are given in italic.

regulatory element in the $\mathrm{XX}$ gonads is responsible for a female-to-male sex reversal.

Currently, we are trying to confirm the hypothetical roles of the three genes by transgenesis experiments in goats.

\section{GENETICS OF BPES IN HUMANS}

BPES is a genetic autosomal dominant disease which associates an eyelid malformation (in both sexes) and an ovarian dysgenesis responsible for a primary amenorrhea in 46, XX women (Fig. 3). As described above, the BPES mutation is located on human chromosome 3 (band q23), homologous to the PIS region in goats. Recently FOXL2 has been shown to be responsible for BPES [5].

FOXL2 is a single-exon gene encoding a transcription factor presenting a "forkhead" DNA binding domain. FOXL2 protein also has a polyalanine tract $(n=14)$ with a currently unknown function. Noteworthy, $30 \%$ of mutations consist in the expansion of this poly-ALA tract. The FOXL2 gene is highly conserved among all studied vertebrates; however its conservation is more pronounced in the C-terminal domain rather than in the $\mathrm{N}$-terminal part of the protein. This high conservation is also found in fish like Fugu, Tilapia and Trout.
The expression of FOXL2 has been analyzed with a polyclonal antibody. In humans, we detected the FOLX2 protein in the nucleus of fetal eyelid muscular cells and in the nucleus of fetal granulosa cells. On the contrary, FOXL2 could not be detected neither in the oocyte, nor in the fetal or adult testes. Identical results have been observed in the mouse, goat, chicken and fish $[9,10]$.

\section{FOXL2: AN OVARIAN DIFFERENTIATING GENE}

The expression of FOXL2 takes place at an early stage in the development of mammal ovaries. Indeed, it has been detected in $\mathrm{XX}$ genital ridges. This observation suggests that FOXL 2 could be an ovarian determining gene. Nevertheless, Foxl2 invalidation was reported in 2004: the heterozygous Foxl2 ${ }^{+/-}$mice have a normal phenotype [11, 12]. However, the homozygous Foxl2 $2^{-/}$has a phenotype similar to the one observed in BPES patients. These mice present eyelid malformation and the females develop sterility while males remain fertile. Even displaying a normal ovarian differentiation at birth, XX Foxl2 $2^{--}$mice later develop premature ovarian failure. This failure is due to altered differentiation of granulosa cells which are not able to form follicles. Consequently, Foxl2 KO-mice are an excellent animal model of human BPES. This model will allow us to study the mechanism of primary amenorrhea in BPES patients.

\section{FOXL2 IN FISHES}

The rainbow trout is an interesting model for the study of Foxl2 for the following reasons: (i) the trout genome went through a tetraploid phase, then a diploid phase in evolution; (ii) sexual differentiation, even genetically controlled by an XY/XX mechanism, can be modified by environmental factors such as hormones, leading to the development of fertile neo-XX males or neo-XY females. 


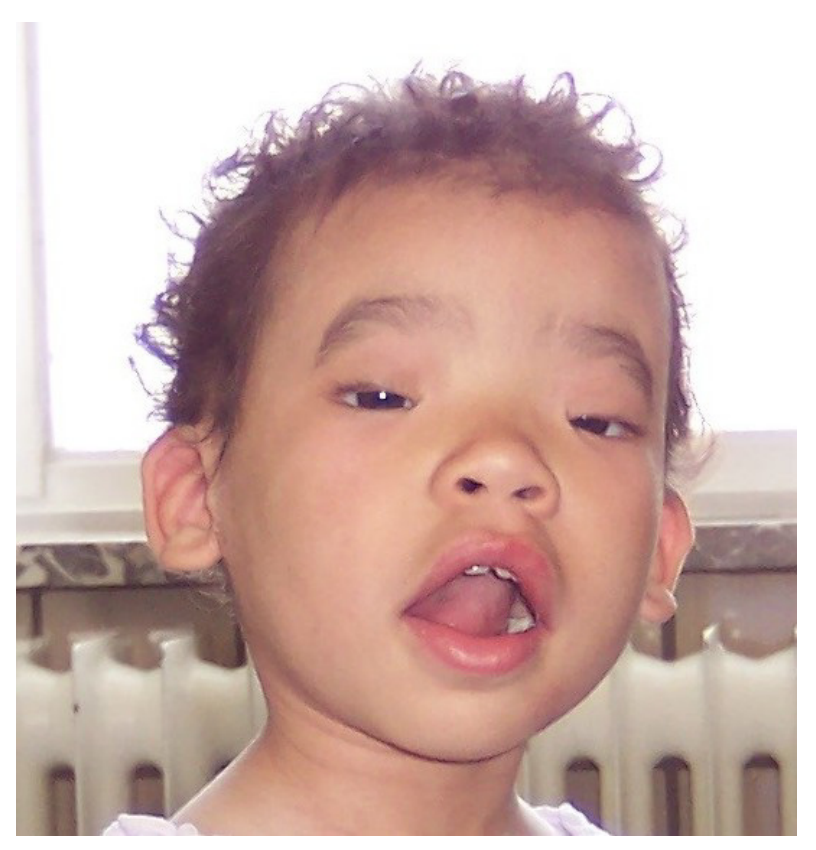

Figure 3. Facial dysmorphy of a BPES patient. Facial malformations in BPES syndrome associating ptosis and epicantus.

The study of the FOXL2 gene in trout led us to two main conclusions:

1. There are two FOXL2 genetically independent paralogue genes: FOXL2a and FOXL2b. FOXL2a expression is similar to that observed for the mammalian FOXL2 gene. FOXL2b, being specific of somatic cells of the ovary, is expressed later than FOXL2a.

2. The expression of FOXL2 in the ovarian somatic compartment is also found in the ovaries of estrogen-treated neo-XY females. Conversely, FOXL2 expression is not found in androgen-treated neo-XX males. Accordingly, the expression of FOXL2 sharply decreases in XX females treated with aromatase inhibitors [10].

Very recently identical results were obtained in Tilapia.

In conclusion, the FOXL2 gene appears highly conserved in vertebrates regarding its sequence and its expression in the ova- ries. We still have to identify the targets of this transcription factor, which must play an important role in the differentiation of ovarian follicular cells.

\section{REFERENCES}

[1] Cotinot C, Pailhoux E, Ottolenghi C, Veitia R, Fellous M. Le déterminisme du sexe: son contrôle génétique. In: Thibault $\mathrm{C}$, Levasseur MC (Eds), La reproduction chez les mammifères et l'homme, INRA, Paris, 2001, p 215-234.

[2] Berta P, Hawkins JR, Sinclair AH, Taylor A, Griffiths BL, Goodfellow PN, Fellous M. Genetic evidence equating SRY and the testisdetermining factor. Nature 1990, 348: 448450 .

[3] Koopman P, Gubbay J, Vivian N, Goodfellow $\mathrm{P}$, Lovell-Badge R. Male development of chromosomally female mice transgenic for Sry. Nature 1991, 351: 117-121.

[4] Pailhoux E, Vigier B, Vaiman D, Servel N, Chaffaux S, Cribiu EP, Cotinot C. Ontogenesis of female-to-male sex-reversal in $\mathrm{XX}$ polled goats. Dev Dyn 2002, 224: 39-50. 
[5] Crisponi L, Deiana M, Loi A, Chiappe F, Uda M, Amati P, Bisceglia L, Zelante L, Nagaraja R, Porcu S, Ristaldi MS, Marzella R, Rocchi M, Nicolino M, Lienhardt-Roussie A, Nivelon A, Verloes A, Schlessinger D, Gasparini P, Bonneau D, Cao A, Pilia G. The putative forkhead transcription factor FOXL2 is mutated in blepharophimosis/ptosis/epicanthus inversus syndrome. Nat Genet 2001, 27: 159-166.

[6] Pailhoux E, Vigier B, Chaffaux S, Servel N, Taourit S, Furet JP, Fellous M, Grosclaude F, Cribiu EP, Cotinot C, Vaiman D. A $11.7 \mathrm{~kb}$ Deletion triggers intersexuality and polledness in goats. Nat Genet 2001, 29: 453-458.

[7] Coquet J, Pailhoux E, Jaubert F, Servel N, Xia X, Pannetier M, De Baere E, Messiaen I, Cotinot C, Fellous M, Veitia R. Evolution and expression of fox12. J Med Genet 2002, 39: 916-922.

[8] Cocquet J, De Baere E, Gareil M, Pannetier M, Xia X, Fellous M, Veitia R. Structure, evolution and expression of fox 12 transcription unit. Cytogenet Genome Res 2003, 101: 206-211.
[9] Govoroun M, Pannetier M, Pailhoux E, Cocquet J, Brillard JP, Couty I, Batellier F, Cotinot C. Isolation of chicken homolog of foxl2 gene and comparison of its expression patterns with those of aromatase during ovarian development. Dev Dyn 2004, 231: 859870.

[10] Baron D, Cocquet J, Xia X, Fellous M, Guiguen Y, Veitia RA. An evolutionary and functional analysis of FoxL2 in rainbow trout gonad differentiation. J Mol Endocrinol. 2004, 33: 705-715.

[11] Schmidt D, Ovitt CE, Anlag K, Fehsenfeld S, Gredsted L, Treier AC, Treier M. The murine winged-helix transcription factor Foxl2 is required for granulosa cell differentiation and ovary maintenance. Development 2004, 131: 933-942.

[12] Uda M, Ottolenghi C, Crisponi L, Garcia JE, Deiana M, Kimber W, Forabosco A, Cao A, Schlessinger D, Pilia G. Foxl2 disruption causes mouse ovarian failure by pervasive blockage of follicle development. Hum Mol Genet 2004, 13: 1171-1181. 